\title{
Challenges in dengue surveillance and control
}

Lee Ching $\mathrm{Ng}^{*}$

\section{RESURGENCE OF DENGUE}

Globally, the challenge posed by dengue has escalated at an astonishing rate in the last three decades, with no sign of abating. It is estimated that dengue affects at least 50 million - 100 million people every year. With more than 120 dengue-endemic countries, 3.6 billion people are at risk of infection. ${ }^{1}$ More than $70 \%$ of those at risk reside in the Asia Pacific region, making this region an epicentre of dengue activity.

In addition to making a comeback in places such as the Americas and Singapore, where dengue was previously successfully controlled for decades, ${ }^{2,3}$ the virus has also breached the subtropical-temperate barrier as it claims new territories. In the last decade, dengue transmission has extended its reach into places as far north as Nepal, ${ }^{4}$ Ningbo in China ${ }^{5}$ and France, ${ }^{6}$ and as far south as Bueno Aires in Argentina. ${ }^{7}$ The Pacific islands, with much lower population densities, have also not been spared, with increasing dengue outbreaks since the $1970 s^{8}$

The direct economic and social impact of dengue on dengue-endemic regions is high, ${ }^{9-12}$ and the burden in other aspects such as the security of blood supplies is increasingly being recognized. ${ }^{13}$ Dengue's threat to travellers has also been systematically demonstrated by a 2008 study on 6957 travellers who returned ill and sought treatment from EuroTravNet centres. Of those travellers, $1.9 \%$ were diagnosed with dengue, and one of the three deaths reported was due to dengue shock syndrome. ${ }^{14}$

\section{FACTORS THAT CONTRIBUTED TO THE CHALLENGE}

Key contributing factors to the worldwide resurgence of dengue in the last few decades include the rise in number and size of densely populated urban cities that are conducive for the spread of the disease and the adaptation and proliferation of dengue vectors, particularly the primary carrier of dengue virus, Aedes aegypti. In the last three decades, the number of people living in cities around the world has doubled from 1.7 billion to 3.5 billion. The number is expected to rise to 5 billion by 2030 , and most of this is projected to occur in Asia. ${ }^{15}$ Furthermore, increased global travel has facilitated the spread of the virus. The resultant increase in transmission of the viruses has brought about genetic expansion of virus, providing ample opportunities for successful selections of viral variants of high epidemic potential or virulence as suggested by molecular epidemiological studies on Cuba and Puerto Rico. ${ }^{16,17}$ The geographical expansion of the vector, Aedes aegypti, is also well demonstrated by its recent invasion or reinvasion into temperate regions, such as Nepal and Bueno Aires in Argentina, ${ }^{4,18}$ and into rural areas in Indonesia and Cambodia. ${ }^{19,20}$ The vectorial role of Aedes albopictus, a mosquito that has successfully established its territory from South-East Asia to northern Asia (Japan and China), the Americas and Europe, has also been clearly revealed by dengue outbreaks in many places such as Hawaii, Hong Kong (China) and Ningbo, China. ${ }^{5,21}$

Dengue vaccine is not available, and its development is hindered by the lack of suitable animal models and the requirement for a robust tetravalent vaccine that covers all four serotypes of dengue. With only one vaccine in the third phase of clinical trial, it is estimated that a dengue vaccine will not be available for at least the next seven years. Vector control remains the key strategy in dengue prevention and control. Unfortunately, the extensive and often indiscriminate use of insecticides has resulted in a global pandemic of insecticide resistance.

\section{STRATEGY}

The urban and peridomestic habitats of Aedes aegypti offer an opportunity to suppress the vector population through source reduction, careful environment

* Environmental Health Institute, National Environment Agency, Singapore (e-mail: NG_Lee_Ching@nea.gov.sg) doi: 10.5365/wpsar.2011.2.2.001 
management and urban planning to deprive the Aedes mosquitoes of stagnant water for breeding. The success of this strategy has been demonstrated in the Americas and in Singapore in the 1950s and 1960s; Aedes aegypti was either eradicated or suppressed to a population that eliminated dengue or moderated dengue transmission to low endemicity. However, the recent resurgence has shown the limitation of the traditional strategy. It calls for more innovations and a better framework for surveillance and control.

\section{INTER-EPIDEMIC SURVEILLANCE AND CONTROL}

To battle with a complex disease like dengue, four cornerstones are required to support a robust surveillance system: human cases, virus, entomological and ecological surveillance. ${ }^{22}$ Today's better understanding of the epidemiology of dengue, coupled with technologies such as geographical information systems, polymerase chain reaction, rapid antigen test kits, sequencing and bioinformatics, have offered us an opportunity to take a holistic approach in our undertaking to suppress the resurgence of dengue.

\section{UNITED IN TACKLING EPIDEMIC DENGUE}

Dengue does not respect political boundaries; neither does it respect divisions of government agencies or communities. Formation of linkages among those entities is critical for success of control programmes and is consistent with the Integrated Vector Management strategy promoted by the World Health Organization (WHO). Intersectoral linkage is critical to ensure that the activities of other sectors such as urban development, agriculture or water resources do not compromise any vector control programme; instead, vector control should be an agenda of each sector. The complexity of the disease also requires concerted effort among laboratory personnel of multi-disciplines, field officers, policy-makers and the community. The stakeholders are many in the control of dengue. An effective programme requires effective communications among various stakeholders, with elements of feedback and data sharing. The chain of events and measures that support surveillance, clinical management and control is not unlike a chain of links - the chain is only as strong as its weakest link.
Recognizing the importance of cross border-linkages, the Asia Pacific Dengue Partnership was formed in March 2006 to support and facilitate effective implementation of a prevention and control strategy so as to reverse the rising trend of dengue in the Asia Pacific region. Under the Partnership, Member States of the Western Pacific and South-East Asia Regions joined efforts with WHO in formulating the 2008-2015 Bi-Regional Dengue Strategic Plan, which was subsequently endorsed by the Regional Committees in September 2008, to be employed as a road map for national plans. Several activities, including the Asia Pacific Dengue Programme Managers' Meeting and Asia Pacific Dengue Workshops, have been conducted to support the Plan in knowledge exchange and capacitybuilding. ${ }^{23,24}$ The recently updated Asia Pacific Strategy for Emerging Diseases, known as APSED (2010), provides a common strategic framework for countries and partners to work collectively to strengthen the national and regional disease surveillance and response systems and capacities, including dengue surveillance, outbreak response, clinical management and risk communications. ${ }^{25}$

Despite progress made, many challenges remain, including: standardization of classification of dengue, enhancement of cases, vector and virus surveillance, limited resources and infrastructure for surveillance and control, quality of diagnostics, limited access to good clinical care, need for more advance entomological tools and the limited research that are eventually translated to disease prevention and management. Dengue is a serious problem that is already challenging us, and it threatens to be more aggressive. More support, attention, action and synergistic collaboration among all stakeholders are urgently needed to enhance the current systems.

\section{Reference:}

1. Dengue in the Western Pacific Region. Manila, World Health Organization, 2009 (http://www.wpro.who.int/health_topics/ dengue/, accessed on 8 March 2011).

2. Koh BKetal. The 2005 dengue epidemic in Singapore: epidemiology, prevention and control. Annals of the Academy of Medicine, Singapore, 2008, 37:538-545. pmid:18695764

3. Guzman MG, Kouri G. Dengue and dengue hemorrhagic fever in the Americas: lessons and challenges. Journal of Clinical Virology, 2003, 27:1-13. doi:10.1016/S1386-6532(03)00010-6 pmid: 12727523

4. Pandey $\mathrm{BD}$ et al. Dengue virus, Nepal. Emerging Infectious Diseases, 2008, 14:514-515. doi:10.3201/eid1403.070473 pmid: 18325280 
5. Xu G et al. An outbreak of dengue virus serotype 1 infection in Cixi, Ningbo, People's Republic of China, 2004, associated with a traveler from Thailand and high density of Aedes albopictus. The American Journal of Tropical Medicine and Hygiene, 2007, 76:1182-1188. pmid:17556633

6. Gould EA et al. First cases of autochthonous dengue fever and chikungunya fever in France: from bad dream to reality! Clinical Microbiology and Infection, 2010, 16:1702-1704. doi:10.1111/ j.1469-0691.2010.03386.x pmid:21040155

7. Natiello $M$ et al. Indigenous dengue fever, Buenos Aires, Argentina. Emerging Infectious Diseases, 2008, 14:1498-1499. doi:10.3201/eid1409.080143 pmid:18760035

8. Singh $\mathrm{N}$ et al. Dengue in the Pacific-an update of the current situation. Pacific Health Dialog, 2005, 12:111-119. pmid:18181502

9. Anderson KB et al. Burden of symptomatic dengue infection in children at primary school in Thailand: a prospective study. Lancet, 2007, 369:1452-1459. doi:10.1016/S0140-6736(07)606710 pmid: 17467515

10. Beauté J, Vong S. Cost and disease burden of dengue in Cambodia. BMC Public Health, 2010, 10:521. doi:10.1186/1471-245810-521 pmid:20807395

11. Garg $\mathrm{P}$ et al. Economic burden of dengue infections in India. Transactions of the Royal Society of Tropical Medicine and Hygiene, 2008, 102: 570-577. doi:10.1016/j.trstmh.2008.02.015 pmid:18402995

12. Halstead SB, Suaya JA, Shepard DS. The burden of dengue infection. Lancet, 2007, 369:1410-1411. doi:10.1016/S01406736(07)60645-X pmid:17467495

13. Ng LC, Lam S, Teo D. Epidemiology of dengue and chikungunya viruses and their potential impact on the blood supply. ISBT Science Series, 2009, 4:357-367. doi:10.1111/j.17512824.2009.01274.x

14. Field $V$ et al.; EuroTravNet network. Travel and migration associated infectious diseases morbidity in Europe, 2008. BMC Infectious Diseases, 2010, 10:330. doi:10.1186/1471-233410-330 pmid:21083874

15. World Urbanization Projects: the 2001 Revision Data Tables and Highlights. New York, United Nations Secretariat, 2002
58-59 (http://www.un.org/esa/population/publications/wup2001/ WUP2001Annextab.pdf., accessed on 5 April 2011).

16. Rodriguez-Roche $\mathrm{R}$ et al. Virus role during intraepidemic increase in dengue disease severity. Vector Borne Zoonotic Disease, 2011 (http://www.liebertonline.com/doi/abs/10.1089/vbz.2010.0177, accessed on 5 April 2011).

17. Bennett SN et al. Molecular evolution of dengue 2 virus in Puerto Rico: positive selection in the viral envelope accompanies clade reintroduction. Journal of General Virology, 2006, 87:885-893. doi:10.1099/vir.0.81309-0 pmid:16528038

18. Avilés $G$ et al. Dengue reemergence in Argentina. Emerging Infectious Diseases, 1999, 5:575-578. doi:10.3201/ eid0504.990424 pmid:10460181

19. Seng CM et al. Community-based use of the larvivorous fish Poecilia reticulata to control the dengue vector Aedes aegypti in domestic water storage containers in rural Cambodia. Journal of Vector Ecology, 2008, 33:139-144. doi:10.3376/10811710(2008)33[139:CUOTLF]2.0.CO;2 pmid:18697316

20. Jumali et al. Epidemic dengue hemorrhagic fever in rural Indonesia. III. Entomological studies. The American Journal of Tropical Medicine and Hygiene, 1979, 28:717-724. pmid:464193

21. Effler PV et al.; Hawaii Dengue Outbreak Investigation Team. Dengue fever, Hawaii, 2001-2002. Emerging Infectious Diseases, 2005, 11:742-749. pmid:15890132

22. Lee KS et al. Dengue virus surveillance for early warning, Singapore. Emerging Infectious Diseases, 2010, 16:847-849. pmid:20409381

23. Asia-Pacific Dengue Programme Managers Meeting, 2008. Manila, World Health Organization Western Pacific Regional Office, $2008 \quad$ (http://www.wpro.who.int/internet/files/mvp/ Dengue_Report.pdf, accessed on 8 March 2011).

24. Report on First Asia-Pacific Dengue Workshop. Singapore, Environmental Health Institute, 2009 (http://app2.nea.gov.sg/ data/cmsresource/20091022145757271094.pdf, accessed on 8 March 2011).

25. Asia Pacific Strategy for Emerging Diseases (2010). Manila World Health Organization - South-East Asia Region and Western Pacific Region, 2011 (http://www.wpro.who.int/internet/ resources.ashx/CSR/Publications/ASPED 2010.pdf, accessed on 8 March 2011). 